\title{
QUALITY EVALUATION OF PARACETAMOL IN THE BULK, DOSAGE FORMS AND BODY FLUIDS USING THE HIGH PERFORMANCE LIQUID CHROMATOGRAPHY (HPLC) TECHNIQUE
}

\author{
S. Asare-Nkansah and J.K. Kwakye \\ Department of Pharmaceutical Chemistry, \\ Faculty of Pharmacy and Pharmaceutical Sciences, \\ Kwame Nkrumah University of Science and Technology, Kumasi, Ghana
}

\begin{abstract}
High Performance Liquid Chromatography has been used to evolve an analytical procedure for the evaluation of the content of paracetamol in the bulk, dosage forms and in urine, a body fluid. Separation and resolution have been achieved with a combination of methanol and $2.5 \%$ acetic acid (15:85) on a reversed-phase column at ambient temperature. Elution was isocratic with $U V$ detection at $257 n m$. Internal standard calibration method was used for quantitation with caffeine as the internal standard. Mean retention times for paracetamol and caffeine were respectively $2.61 \pm 0.13$ min and $11.98 \pm 0.72$ min . The calibration curve was linear over the range $0.1-5.0 \mu g / m l$. The method was also suitable for the assay of paracetamol-codeine combination drug as well as estimation of the amount of constituents in urine when the wavelength of $U V$ detection was $245 \mathrm{~nm}$ with acetanilide as the internal standard.
\end{abstract}

Keywords: Chromatography, isocratic, internal standard, in vivo and in vitro

\section{INTRODUCTION}

Paracetamol (N-(4-hydroxyphenyl) acetamide) tablets are listed among the essential drugs selected for the health care delivery system in Ghana.<smiles>CC(=O)Nc1ccc(O)cc1</smiles>

Figure 1: Chemical Structure of Paracetamol

Paracetamol is very much used for antipyresis and analgesia without prescription. The drug is useful in mild to moderate pain such as headache, myalgia and postpartum pain. It is a very good alternative for mild to moderate pain in patients who cannot take aspirin because of allergy, haemophilia, history of peptic ulcer and asthma. (Katzung, 1989).

As a result of the Ghana government's policy of generic prescribing, the liberalization of trade and import laws, and the ever-increasing number of pharmaceutical industries, a wide range of paracetamol products appear on the Ghanaian market. According to the Ghana National Drugs Policy, only drugs conforming to nationally accepted and/or internationally recognized quality standards shall be permitted to be procured and distributed in the country (Ghana National Drugs Policy, 1999). Any study therefore designed to monitor and improve the quality evaluation of pharmaceutical products both at the time of registration and post-market is very essential in the policy and technical guidelines of drug regulatory authorities such as the Food and Drugs Board. Such a study also benefits the Ghana Health Service in the sense that procurement staff, prescribers, dispensers and patients have access to high-quality and efficacious drug products. Pharmaceutical industries may also have simple analytical procedures for both in-process and finished product evaluations.

The HPLC has been used to determine paracetamol in tablets. Franeta et al (2002) used the HPLC for the 
simultaneous determination of acetylsalicylic acid, paracetamol, caffeine and phenobarbital in tablets on a reversed-phase column using a mixture of acetonitrile and water $(25: 75 \mathrm{v} / \mathrm{v})$ adjusted to $\mathrm{pH} 2.5$ with phosphoric acid.

The Bio Rad 1801 UV-Vis detector was used (207 nm). Ramos-Martos et al (2001) also described a rapid reversed-phase HPLC method with UV detection for the simultaneous determination of acetylsalicylic acid, caffeine, codeine, paracetamol, pyridoxine and thiamine in pharmaceutical preparations using two successive eluants of water for 5 minutes and acetonitrile-water (75: $25 \mathrm{v} / \mathrm{v})$ for 9 minutes, both eluants adjusted to $\mathrm{pH} 2.1$ with phosphoric acid. Codeine was determined at $240 \mathrm{~nm}$ whilst the rest were detected at $285 \mathrm{~nm}$. Okine et al (2003) used a mixture of methanol and $0.05 \mathrm{M} \mathrm{NaH} \mathrm{NO}_{4}(17: 83)$, pH 2.0 with UV detection $(273 \mathrm{~nm})$ for eluting ascorbic acid, paracetamol and caffeine combined in a tablet. Apart from the high cost of acetonitrile for routine analysis, the systems were not selective for unchanged paracetamol in urine. It therefore becomes imperative to evolve a system that is cost effective and selective for paracetamol in the bulk powder, dosage forms and biological fluids such as blood and urine for easier routine in vitro and in vivo monitoring of drug samples.

EXPERIMENTAL

Components of the Liquid Chromatograph

Pump: Spectra System P100 (Spectra Physics)

Detector: Spectra 100 Variable Wavelength Detector (Spectra Physics)

Integrator: CR501 Chromatopac (Schimadzu)

Sample Injector: Syringe loading sample injector fitted with an external 20 $\mu 1$ loop (Model no. 8125-095)

Stationary phase: Spherisorb HPLC column, $\mathrm{S}_{10}$ ODS2 (10cm, 4.6mm)

\section{Materials}

Pure paracetamol powder (Chemcon GmbH, Germany), Paracetamol tablets (Phyto-Riker Ltd., Ghana), Paracetamol tablets ( PZ Co Ltd., Ghana), Paracetamol tablets (Tylenol Forte, Cilag Ltd., Switzerland), Paracetamol-codeine combination product (Paracod, Phyto-Riker Ltd., Ghana), Paracetamol-codeine combination product (Co-codamol, Alpharma, UK), blank urine sample, deionised water, urine samples with unchanged drug and drug metabolites, methanol (BDH), acetic acid (BDH), potassium dihydrogen phosphate (BDH), caffeine (BDH), salbutamol sulphate (Shubhmets, Mumbai, India), citric acid (Acid India) and phenyl ethanolamine (Blue Bird, Mumbai, India)

\section{Method Design Considerations}

Information on the physico-chemical properties of paracetamol and the other chemicals above were searched. Details considered include solubility properties, chemical structures, acid dissociation constants $\left(\mathrm{pk}_{\mathrm{a}}\right)$, level of purity, stability in solution and ultraviolet light absorption pattern in acidic, basic and neutral media with their respective wavelengths of maximum absorption (Moffat, 1986; British Pharmacopoeia, 2000). The substances were found moderately polar. Based on their polarity, reversed-phase HPLC was considered more applicable because in this mode, a nonpolar stationary phase and a polar mobile phase were utilised so that more polar substances were eluted before the relatively nonpolar. The differences in the physico-chemical properties of paracetamol and the other chemicals aided in selecting an internal standard for the study since they all interacted differently with a chosen combination of mobile phase to give a chromatogram of different separations, resolutions and retention times. Various combinations of methanol/phosphate buffer and methanol/water ( $\mathrm{pH}$ and ionic strength modified with acetic acid) were tried in order to optimise column capacity factor for separation and resolution. Each concentration of phosphate buffer or water (various $\mathrm{pH}$ ) was combined with methanol in various proportions, starting with a 50:50 combination and gradually increasing and decreasing the aqueous content while monitoring their respective effects on separation and resolution. All the mobile phase combinations tried could elute both paracetamol in the bulk powder and tablet matrix with reasonable retention, but not all the other chemicals being considered for an internal standard (caffeine, salbutamol, citric acid and phenyl ethanolamine). Some had poor resolution and tailing peaks while others had poor resolution and unduly long retention times. Some of the mobile phase combinations that could conveniently separate and resolve paracetamol in vitro could not separate and resolve blank urine (urine from a healthy person before drug was administered) spiked with a standard solution of paracetamol. Further altering the combination ratio, ionic strength and $\mathrm{pH}$ of the mobile phase produced the optimum system that could satisfactorily resolve paracetamol in the bulk powder, tablet matrix, spiked blank urine and unchanged paracetamol and other paracetamol metabolites 
excreted in urine. Among the list of chemicals for an internal standard, caffeine was found the best under the optimum chromatographic conditions of the study. The best mobile phase combination was methanol $/ 2.5 \%$ acetic acid $(15: 85)$. Elution was isocratic because a single mobile phase combination was used. After other investigations, the best wavelength of maximum absorption for UV detection was 257 $\mathrm{nm}$, absorption unit fraction scale (aufs) for quantitative detection of the analyte at very small concentrations , 0.5 , flow rate of mobile phase, $1.5 \mathrm{ml} / \mathrm{min}$ and chart recorder speed, $5 \mathrm{~mm} / \mathrm{min}$.

\section{Preparation of mobile phase}

The volume of mixtures do not usually equal the sum of the separate volumes making up the mixture as a result of differences in density and other physical factors such as volume expansion and contraction. The mobile phase was therefore prepared by measuring separately the volume of each component and mixing them together. All mobile phases prepared were filtered through a membrane filter before use.

\section{Validation of Analytical Method}

Various parameters can be evaluated for validating any newly developed analytical system. These include linearity, precision, accuracy, sensitivity and comparison to other standard methods.

Comparison of new method with standard spectrophotometric method, (BP, 2000)

The method was applied to paracetamol products from three pharmaceutical companies. Twenty tablets of each of the experimental paracetamol products were weighed together and finely powdered. A quantity of the powder containing $0.15 \mathrm{~g}$ of paracetamol $(0.1692 \mathrm{~g}$ of Phyto-Riker Paracetamol, $0.1578 \mathrm{~g}$ of PZ Paracetamol and $0.2001 \mathrm{~g}$ of Tylenol Forte) was weighed and quantitatively transferred into a $200 \mathrm{ml}$ volumetric flask with $50 \mathrm{ml}$ of $0.1 \mathrm{M} \mathrm{NaOH}$ and then diluted with $100 \mathrm{ml}$ of distilled water and shaken mechanically for 15 minutes. Sufficient distilled water was then added to produce $200 \mathrm{ml}$. After filtration, further dilutions were made with distilled water such that the final concentration of paracetamol in solution was $0.00075 \% \mathrm{w} / \mathrm{v}$ and the $\mathrm{NaOH}, 0.01 \mathrm{M}$. The absorbance of the resulting solution was then taken in triplicate with the Cecil 7020 double beam UV spectrophotometer at a wavelength of $257 \mathrm{~nm}$ with quartz cuvette of path length $1 \mathrm{~cm}$ using $0.01 \mathrm{M} \mathrm{NaOH}$ as the blank solvent.

\section{New Method}

For each of the experimental brands, sample preparation was done by crushing 20 tablets. A quantity of the powder equivalent to $0.1 \mathrm{~g}$ of paracetamol $(0.1128 \mathrm{~g}$ of Phyto-Riker Paracetamol, $0.1052 \mathrm{~g}$ of PZ Paracetamol and $0.1333 \mathrm{~g}$ of Tylenol Forte) was weighed and quantitatively transferred into a clean $100 \mathrm{ml}$ volumetric flask with $20 \mathrm{ml}$ of methanol. It was then mechanically shaken for 10 minutes. It was diluted to the $100 \mathrm{ml}$ mark with deionised water. Insoluble excipients were filtered off through a medium porosity sintered glass filter. A $0.1 \% \mathrm{w} / \mathrm{v}$ aqueous solution of caffeine was also prepared as a stock internal standard solution. A final solution containing $0.00025 \%$ paracetamol and $0.001 \% \mathrm{w} / \mathrm{v}$ caffeine was prepared for the HPLC analysis. Triplicate injections onto the column were successively done for each of the experimental brands. Average peak area ratios (test sample/internal standard) for the various samples were calculated from their chromatograms. The actual concentration of paracetamol in each of the samples analysed was interpolated from a calibration curve using the average peak area ratios. The student's t-test was used to compare the means of the two methods while the variances were compared with the f-test.

\section{Calibration Graph}

The range of concentrations used was $0.000005 \%-0.001 \% \mathrm{w} / \mathrm{v}$. The new HPLC method was used for the determinations. Injections were done in triplicate for each of the concentrations in the above range. A graph of average peak area ratio was plotted against concentration. All the concentrations used gave signals but not all the signals were proportional to concentration. Concentrations that were not detected proportionally defined the limits of detector linearity under the given set of experimental conditions. Before preparing the solutions for the calibration curve, the paracetamol reference powder was identified and characterised according to BP 2000.

\section{Determination of inter-day variation of analytical method}

The inter-day variation was investigated to assess the likely variations in results from day to day when the new method is used. This involved the HPLC assay of paracetamol of approximately the same concentrations on two different days under same conditions. The results for the two different days were paired and the f-test applied to determine likely significant difference in their variances. 


\section{Determination of intra-day variation of the analytical method}

Several assays of paracetamol were done within the same day to determine the repeatability of the new method. Seven sets of solutions of approximately the same concentration $(0.0001 \% \mathrm{w} / \mathrm{v})$ from the same homogenous stock were prepared and successively analysed with the HPLC. Each set was run three times and the average peak area ratio taken to represent that set. Actual concentrations of solutions were interpolated from the calibration graph. The relative standard deviation of results was calculated to determine the level of repeatability. The concentration of paracetamol solution was so chosen to ensure that readings were taken within the linear region of the calibration curve.

\section{Application of analytical procedure to urine, a body fluid}

After following all pharmacokinetic protocols (Shargel and Andrew, 1993) six healthy male volunteers between the ages of 26 and 32 years were each given $1.0 \mathrm{~g}$ of paracetamol tablets and had their urine samples collected at specific time intervals for 24 hours. All subjects had the same time points of urine collection after administration of the tablets and these were: $0.5,1.0,1.5,2.0,3.0,4.0,5.0,6.0,9.0,12.0$, 18.0 and 24.0 hours. The entire volume of urine voided during each sampling interval was pooled together and recorded and the analysis done immediately. Where urine samples had to be kept overnight, quantities were kept tight in sample tubes and frozen.

\section{Other applications}

The new HPLC method was also applied to a combination product containing paracetamol and codeine both for assay and determination of unchanged forms of the two constituents in urine.

\section{RESULTS AND DISCUSSION}

Since paracetamol is a compound of moderate polarity as shown by its chemical structure in Figure 1, a reversed-phase column with a polar mobile phase was used. The mobile phase was methanol $/ 2.5 \%$ acetic acid (15:85). In reversed-phase separation, compounds were separated based on their hydrophobicity. Retention increased as the solutes decreased in polarity; thus, polar species were eluted first. Hence, eluting time increased by increasing the polarity (water content) of the eluent. The $\mathrm{pH}$ of the eluent as well as the pka of the drug being separated affected the elution profile. Figures 2 (a-c) therefore show different elution profiles and retention times because of the differences in the physicochemical properties of the analytes under review. The retention time of caffeine $(11.98 \pm 0.72 \mathrm{~min})$ was greater than paracetamol $(2.61 \pm 0.13$ $\min$ ) because it was greatly retained on the column as evidenced by the tailing nature of the caffeine peak because of its relatively greater hydrophobicity. The components of the blank urine though poorly resolved, had shorter retention times $(<2.5 \mathrm{~min})$ than paracetamol because they were relatively more polar and interacted better with the polar mobile phase, resulting in decreased retention.

Figure 2 (a): Chromatogram of blank urine

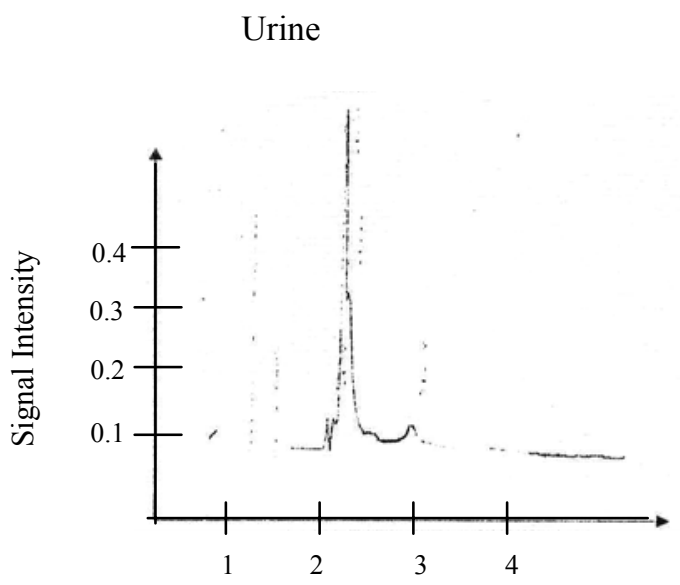


Figure 2 (b): Chromatogram of excreted paracetamol and caffeine

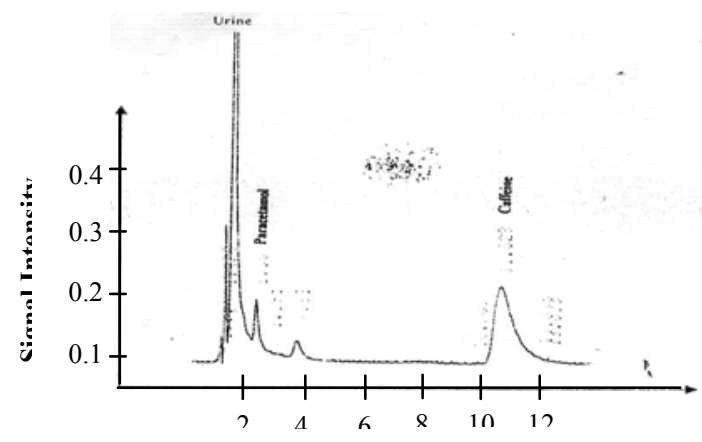

Retention Time (Minutes)

Figure 2 (c): Chromatogram of reference paracetamol and caffeine

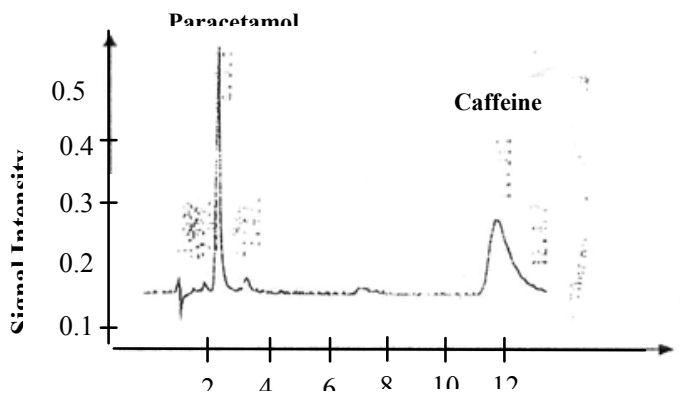

Retention Time (Minutes)

The presence of aromatic rings together with auxochromes in the chemical structures of paracetamol and caffeine made UV absorption possible for monitoring the column effluent.

As regards the intra-day precision of the new method, the relative standard deviation (RSD) of repeated assay of separate identical samples of concentration $1 \mu \mathrm{g} / \mathrm{ml}$ was $2.17 \%$ (Table 1 and 2).

According to Dong (2000), only HPLC analysis with modern auto samplers yields RSD of less than $2.0 \%$. Manual sample injections with RSD of 2.17 can therefore not be said to have a poor potential to give reproducible data under the same experimental conditions. Random errors from analysts might as well have contributed to the RSD value being greater than $2.0 \%$. The degree of agreement among the individual observations was indicated by the value of the absolute precision (0.02). This appears small and suggests a good level of agreement between test results. The inter-day precision from Table 3 and 4 was high as there was no statistical difference between the variances of the set of analytical data generated for two different days at a confidence level of $95 \%$. The method therefore was reproducible and could produce data for peer analysis.

Table 1: HPLC data for intra-day assay of $1 \mu \mathrm{g} / \mathrm{ml}$ solution of paracetamol

$\begin{array}{ccc}\text { Number of run } & \text { Mean Peak Area Ratio } & \text { Conc. }(\mathbf{m c g} / \mathbf{m l}) \\ 1 & 0.2295 & 0.974 \\ 2 & 0.2279 & 0.968 \\ 3 & 0.2209 & 0.938\end{array}$

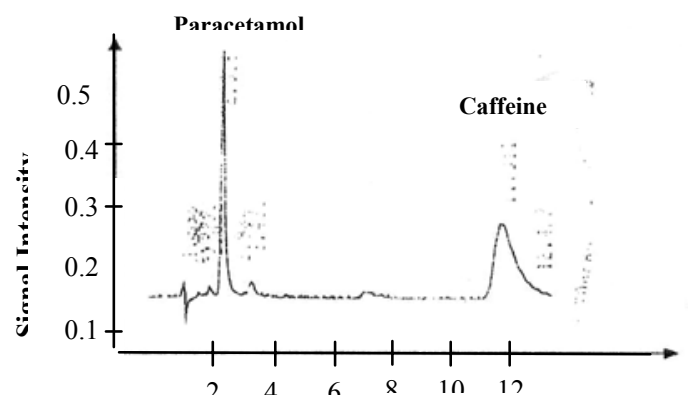

Retention Time (Minutes) 


\begin{tabular}{lll}
4 & 0.2326 & 0.987 \\
5 & 0.2360 & 1.001 \\
6 & 0.2251 & 0.956 \\
7 & 0.2254 & 0.957 \\
\hline
\end{tabular}

Table 2: Statistical analysis of intra-day measurements of $1 \mu \mathrm{g} / \mathrm{ml}$ solution of paracetamol

\begin{tabular}{cccccccc}
\hline $\begin{array}{c}\text { Mean } \\
\text { Concentration }\end{array}$ & Std. Dev & $\begin{array}{c}\text { Rel. } \\
\text { Std. } \\
\text { Dev }\end{array}$ & SEM $^{1}$ & $\begin{array}{c}\text { Absolute } \\
\text { Precision }\end{array}$ & $\begin{array}{c}\text { Confidence } \\
\text { limits of the } \\
\text { mean }\end{array}$ & $\begin{array}{c}\text { Absolute } \\
\text { error of the } \\
\text { method }\end{array}$ & $\begin{array}{c}\text { Relative } \\
\text { error of the } \\
\text { method }\end{array}$ \\
$0.969 \mu \mathrm{g} / \mathrm{ml}^{3}$ & $0.021 \mu \mathrm{g} / \mathrm{ml}$ & $\begin{array}{c}\text { 2.17\% } \\
\text { med }\end{array}$ & 0.008 & 0.020 & $0.969 \pm 0.02 \mu \mathrm{g} / \mathrm{ml}$ & $0.023 \mu \mathrm{g} / \mathrm{ml}$ & $2.32 \%$ \\
\hline
\end{tabular}

1. SEM: standard error of the mean

2. Confidence level for the computation of absolute precision of data and confidence limits of the mean was $95 \%$

3. Percentage purity of paracetamol reference powder was 99.92

There was a positive correlation between peak area ratios and the concentrations of analyte (Figure 3). Correlation coefficient $\left(\mathrm{r}^{2}\right)$ of 0.9998 implies that the scatter presented in Figure 3 was accurate enough for predictable purposes within limits of detector linearity. From Table 5, the range of detector linearity was established as $0.1-5.0 \mu \mathrm{g} / \mathrm{ml}$. Under the set of experimental conditions, the lowest concentration of paracetamol that was detected but did not necessarily produce a signal that was proportional to concentration was $0.05 \mu \mathrm{g} / \mathrm{ml}$. However, signal for $0.2 \mu \mathrm{g} / \mathrm{ml}$ paracetamol solution was approximately twice that of $0.1 \mu \mathrm{g} / \mathrm{ml}$. Since the minimum concentration of paracetamol that started varying proportionally with peak area ratio was $0.1 \mu \mathrm{g} / \mathrm{ml}$, it was chosen as the limit of quantitation of the method. This observation was in good agreement with what has been reported that in many cases, the limit of quantitation is approximately twice the limit of detection (Sethi, 1993; Olaniyi, 2000). The upper limit of quantitation was also set at $5.0 \mu \mathrm{g} / \mathrm{ml}$ because there was no proportional increase in peak area on increasing paracetamol concentration from 5 to $10 \mu \mathrm{g} / \mathrm{ml}$.

Table 5: HPLC Data for finding limits of UV detector linearity

\begin{tabular}{|c|c|c|c|}
\hline \multirow{3}{*}{$\begin{array}{c}\text { Conc. of } \\
\text { paracetamol } \\
(\mu \mathrm{g} / \mathrm{ml})\end{array}$} & \multicolumn{3}{|c|}{ Peak Area Ratio } \\
\hline & \multicolumn{2}{|c|}{$\begin{array}{l}\text { Number of set of } \\
\text { Determinations }\end{array}$} & \multirow[t]{2}{*}{ Mean } \\
\hline & 1 & 2 & \\
\hline 0.05 & 0.0186 & 0.0133 & $\begin{array}{c}0.01595 \pm \\
0.003\end{array}$ \\
\hline 0.10 & 0.0245 & 0.0160 & $0.0203 \pm 0.004$ \\
\hline 0.20 & 0.0444 & 0.0407 & $0.0426 \pm 0.002$ \\
\hline 0.50 & 0.1059 & 0.1148 & $0.1104 \pm 0.004$ \\
\hline 1.00 & 0.2288 & 0.2384 & $0.2336 \pm 0.005$ \\
\hline 2.00 & 0.4917 & 0.4855 & $0.4886 \pm 0.003$ \\
\hline 5.00 & 1.1502 & 1.2268 . & $1.1885 \pm 0.039$ \\
\hline 10.00 & 1.1718 & 1.3436 & $1.2577 \pm 0.086$ \\
\hline
\end{tabular}


Table 6: Comparison of variances and means of HPLC and UV analyses (n=3)

\begin{tabular}{|c|c|c|c|c|c|c|}
\hline \multirow[b]{2}{*}{$\begin{array}{c}\text { Analytical } \\
\text { Method }\end{array}$} & \multicolumn{3}{|c|}{ F-test $\left(v_{1}, v_{2}=2\right)^{1} ; 95 \%$} & \multicolumn{3}{|c|}{ t-test $(95 \%, 4)$} \\
\hline & $\mathbf{F}_{\text {calculated }}$ & $\mathbf{F}_{\text {critical }}$ & $\begin{array}{c}\text { Comment } \\
\text { on } \mathbf{H}_{0}\end{array}$ & $\mathbf{t}_{\text {calculated }}$ & $\mathbf{t}_{\text {critical }}$ & $\begin{array}{c}\text { Comment } \\
\text { on } \mathrm{H}_{0}\end{array}$ \\
\hline $\begin{array}{c}\text { HPLC } \\
\text { UV }\end{array}$ & 1.24 & $39.00^{2}$ & $\begin{array}{c}\mathrm{F}_{\text {calculated }}< \\
\mathrm{F}_{\text {critical }}, \mathrm{H}_{\mathrm{o}} \text { is } \\
\text { valid }\end{array}$ & 3.02 & $2.78^{2}$ & $\begin{array}{l}\mathrm{t}_{\text {calculated }}> \\
\mathrm{t}_{\text {critical }}, \mathrm{H}_{\mathrm{o}} \text { is } \\
\text { invalid }\end{array}$ \\
\hline
\end{tabular}

$v_{1}, v_{2}$ are the degrees of freedom of the numerator (UV) and denominator (HPLC) respectively

Miller, J. C. and Miller, J. N. (1993), Statistics for Analytical Chemistry, 3rd edition

Evidence of correlation between the new method and that of British Pharmacopoeia (2000) for the assay of paracetamol tablets was positive. The F-test at 95\% confidence level, showed no significant difference between the variances of both the HPLC and UV methods (Table 6). This means that within certain limits, both methods have comparable precisions. However, the absolute precision of the two methods at the same confidence level indicates that the HPLC method has a better precision. The absolute precision values were respectively 1.90 and 2.12 (Table 7). As regards accuracy, even though the results of both methods complied with BP (2000) limits for content of paracetamol in tablets (Table 8), a significant difference was observed between the means of the two methods when the student's t-test was applied (Table 6). Assessing the absolute error of the mean for the two methods, the HPLC results $(2.3 \%)$ was found to be more accurate than the UV (4.3\%) (Table 7).

Table 7: Statistical analysis of mean \% content of paracetamol from HPLC and UV assays (n=3)

\begin{tabular}{lcc}
\multicolumn{1}{c}{ Statistical parameter } & \multicolumn{2}{c}{ Analytical Method } \\
& HPLC & UV \\
Mean \% Content ${ }^{1}$ & 102.28 & 104.30 \\
Absolute error (\%) & 2.3 & 4.3 \\
Standard deviation & 0.766 & 0.854 \\
Standard error of the mean & 0.442 & 0.493 \\
Absolute precision at 95\% Confidence level & 1.90 & 2.12 \\
\hline
\end{tabular}

1. From BP (2000), mean percentage content of Paracetamol tablets is 100.0

Table 8: Comparison of mean \% content of different brands of paracetamol using HPLC and UV

\begin{tabular}{ccc} 
Sample Code & \multicolumn{3}{c}{ Analytical Method } \\
& Mean \% Content (HPLC) & Mean\% Content (UV, 257nm)) \\
Paracetamol CoA & 101.43 & 103.32 \\
Paracetamol CoB & 102.92 & 104.90 \\
Paracetamol CoC & 102.48 & 104.67
\end{tabular}

1. Content of paracetamol tablets BP (2000): 95.0-105.0\%

Table 9: Cumulative amounts of paracetamol excreted in urine $(n=6)$

\begin{tabular}{|c|c|c|c|}
\hline \multirow[t]{3}{*}{ Time (hr) } & \multicolumn{3}{|c|}{ Mean cumulative amount excreted (mg) ${ }^{1}$} \\
\hline & \multicolumn{3}{|c|}{ Products } \\
\hline & Paracetamol CoA & Paracetamol CoB & Paracetamol CoC \\
\hline 0.0 & 0.00 & 0.00 & 0.00 \\
\hline 0.5 & $3.68 \pm 1.9$ & $1.28 \pm 0.7$ & $2.68 \pm 1.6$ \\
\hline 1.0 & $10.40 \pm 4.0$ & $5.58 \pm 2.2$ & $7.20 \pm 3.0$ \\
\hline
\end{tabular}

$v_{1}, v_{2}$ are the degrees of freedom of the numerator (UV) and denominator (HPLC) respectively Miller, J. C. and Miller, J. N. (1993), Statistics for Analytical Chemistry, 3rd edition 


\begin{tabular}{cccc}
1.5 & $15.38 \pm 4.6$ & $10.35 \pm 3.0$ & $11.05 \pm 4.5$ \\
2.0 & $19.28 \pm 4.5$ & $16.78 \pm 4.7$ & $15.35 \pm 2.9$ \\
3.0 & $25.10 \pm 5.0$ & $24.38 \pm 7.1$ & $20.00 \pm 2.5$ \\
4.0 & $29.08 \pm 6.5$ & $30.40 \pm 8.0$ & $23.73 \pm 2.2$ \\
5.0 & $31.92 \pm 7.2$ & $32.40 \pm 7.6$ & $26.97 \pm 2.3$ \\
6.0 & $34.87 \pm 8.3$ & $35.93 \pm 6.3$ & $29.67 \pm 2.7$ \\
9.0 & $42.43 \pm 8.5$ & $40.35 \pm 6.8$ & $35.28 \pm 4.0$ \\
12.0 & $47.85 \pm 9.5$ & $44.47 \pm 7.1$ & $41.63 \pm 5.1$ \\
18.0 & $51.75 \pm 5.0$ & $48.30 \pm 4.6$ & $45.42 \pm 5.1$ \\
24.0 & $53.01 \pm 9.4$ & $52.85 \pm 11.5$ & $49.98 \pm 7.1$ \\
\% Paracetamol excreted & $5.30 \pm 0.9$ & $5.29 \pm 1.2$ & $5.00 \pm 0.7$ \\
\hline
\end{tabular}

1 Amount of paracetamol administered was $1.0 \mathrm{~g}$

Moffat (1986) reported that when a dose of paracetamol tablets is administered orally, close to $5 \%$ is excreted unchanged in urine. As found in this study, only a small fraction of the absorbed dose was excreted unchanged for all the paracetamol products. These were $5.3 \pm 0.9 \%, 5.3 \pm 1.2 \%$ and $5.0 \pm 0.7 \%$ respectively for Paracetamol CoA, Paracetamol $\mathrm{CoB}$ and Paracetamol $\mathrm{CoC}$ (Table 9). These values are closely in agreement with what has already been reported, making the new method suitable for the detection and quantitation of paracetamol in urine.

\section{CONCLUSIONS}

Paracetamol in the bulk, dosage form and urine has been analysed accurately and precisely by HPLC with Methanol / 2.5\% acetic acid (15: 85) in the reversed-phase mode at a wavelength of $257 \mathrm{~nm}$ using caffeine as the internal standard. The method has also been used for the detection and quantitation of codeine and paracetamol in urine as well as codeine-paracetamol combination tablet. The wavelength of detection in this case was $245 \mathrm{~nm}$ with acetanilide as the internal standard.

\section{REFERENCES}

British Pharmacopoeia (BP) (2000). Volumes I \&II, CD-ROM, The British Pharmacopoeial Commission.

Dong, W. M. (2000). Precision in HPLC. In Today’s Chemist at Work (2000), 9 (8): 28-32.

Franeta, J. T., Agbaba, D., Eric, S., Pavkov, S., Aleksi, M. and Vladimirov, S. (2002). HPLC assay of acetylsalicylic acid, paracetamol, caffeine and phenobarbital in tablets, Farmaco Sep; 57 (9): 709-13

Ghana National Drugs Policy (1999). Ministry of Health, Ghana. pp 4, 7, 12 and 19

Katzung, G. B. (1989). Basic and Clinical Pharmacology, $4^{\text {th }}$ edition, Appleton and Lange, Norwalk, CT. p 444

Moffat, A. C. (1986). Clarke's Isolation and Identification of Drugs, $2^{\text {nd }}$ edition, the Pharmaceutical Press, London. pp 420-421, 849-850

Okine, N.N.A., Asiedu, K.S. and Acheampong, J. (2003). RP-LC determination of ascorbic acid, paracetamol and caffeine in multicomponent anti-cold preparation, Journal of Science and Technology, 23 (1): 55

Olaniyi, A. A. (2000). Principles of Drug Quality Assurance and Pharmaceutical Analysis, Monsuro Publishers, Ibadan, Nigeria.

Ramos-Martos, N., Aguirre-Gomez, F., Molina-Diaz, A., Capitan-Valley, L. F. (2001). Application of liquid chromatography to the simultaneous determination of acetylsalicylic acid, caffeine, codeine, paracetamol, pyridoxine and thiamine in pharmaceutical preparations. J.A.O.C. Int. May-Jun; 84 (3): 676-83

Sethi, P. D. (1993). Quantitative Analysis of Drugs in Pharmaceutical Formulations, $2^{\text {nd }}$ edition, C.B.S Publishers and Distributors, New Delhi. pp 33-37

Shargel, L., Andrew, B. C. Y. (1993). Applied Biopharmaceutics and Pharmacokinetics, $3^{\text {rd }}$ edition, Appleton and Lange, Norwalk, CT. pp 205-209 